\title{
Discovery of Bifunctional Anti-DPP-IV and Anti-ACE Peptides from Housefly Larval Proteins After In silico Gastrointestinal Digestion
}

\author{
Jiun-An Koh ${ }^{1(\mathbb{D})}$, Joe-Hui Ong ${ }^{1(\mathbb{D})}$, Fazilah Abd Manan ${ }^{2(\mathbb{D})}$, Kah-Yaw Ee ${ }^{1,3 \mathbb{C}}$, Fai-Chu Wong ${ }^{1,3(\mathbb{D})}$, \\ Tsun-Thai Chai ${ }^{1,3, *}$ (D) \\ 1 Faculty of Science, Universiti Tunku Abdul Rahman, 31900 Kampar, Perak, Malaysia; jiunan30@1utar.my (J.-A. K.), \\ candy3997@gmail.com (J.-H. O.), eeky@utar.edu.my (K.-Y. E.), wongfc@utar.edu.my (F.-C. W), chaitt@utar.edu.my \\ (T.-T. C.); \\ 2 Department of Biosciences, Faculty of Science, Universiti Teknologi Malaysia, 81310 Skudai, Johor, Malaysia; m- \\ fazilah@utm.my (F.A.M.); \\ 3 Center for Agriculture and Food Research, Universiti Tunku Abdul Rahman, 31900 Kampar, Perak, Malaysia \\ * Correspondence: chaitt@utar.edu.my (T.-T.C.);
}

Received: 6.08.2021; Revised: 12.08.2021; Accepted: 18.08.2021; Published: 17.10.2021

\begin{abstract}
Proteins and peptides of housefly larvae (HFL) have potential applications in food and therapy. The fate of HFL proteins following human gastrointestinal (GI) digestion is unknown. This study adopted a computational approach to discover peptides released from HFL proteins upon GI digestion. In silico digestion of eight major HFL proteins released 783 peptides. This comprised 243 peptides exhibiting 13 types of bioactivities. Ninety-two single-function peptides exhibiting antidipeptidyl peptidase IV (anti-DPP-IV), anti-dipeptidyl peptidase III, anti-angiotensin converting enzyme (anti-ACE), or antioxidant activity were found. Sixty-three multi-function peptides, encompassing 32 bifunctional anti-DPP-IV and anti-ACE peptides, were found. Further screening led to five non-toxic, non-allergenic, high-GI-absorption bifunctional dipeptides: AF, GW, GY, PH, and VF. Molecular docking found the dipeptides to interact with the active site of DPP-IV through hydrophobic interactions. Only GW and VF could bind to the active site of ACE. Thus, the five dipeptides are competitive inhibitors of DPP-IV. GW and VF are potential competitive inhibitors of ACE, whereas AF, GY, and PH are non-competitive inhibitors. Overall, GI digestion could liberate numerous single- and multi-function peptides from HFL proteins. Hence, HFL proteins can be tapped for potential applications in antidiabetic and antihypertension functional food and therapy.
\end{abstract}

Keywords: bioactive peptide, in silico, bioinformatics, housefly larva, dipeptidyl peptidase IV, angiotensin-converting enzyme, BIOPEP

(C) 2021 by the authors. This article is an open-access article distributed under the terms and conditions of the Creative Commons Attribution (CC BY) license (https://creativecommons.org/licenses/by/4.0/).

\section{Introduction}

Bioactive peptides are short peptides encrypted within the structure of a parental protein, which exert biologically relevant activities following their liberation. At present, bioactive peptides which exert anticancer, antidiabetic, antioxidant, antiviral, and many other bioactivities have been documented in the literature [1,2]. Bioactive peptides can be generated by enzymatic hydrolysis, which could happen in vivo during the gastrointestinal (GI) digestion of ingested dietary proteins, or through food processing technology, such as microbial fermentation of protein-rich foods [3]. The past decade has seen a surge in researchers' interest 
in discovering bioactive peptides from diverse biological samples. Bioactive peptides have been identified from edible and non-edible animals [4-6] and plant [7-9] sources. One factor fueling such enthusiasm is the recognition of the potential applications of bioactive peptides as functional food ingredients and therapeutic/prophylactic agents [2, 3].

To date, bioactive peptide discovery is largely driven by wet-lab experimentations that involve the release of bioactive peptides from protein sources, bioactivity-guided purification, mass spectrometric identification of peptide sequences, synthesis of peptides, and validation of bioactivity $[3,10]$. Often, the identification of a few single-function bioactive peptides would be accomplished by such a strategy. Notwithstanding, it is increasingly evident that bioactive peptides can be multifunctional. For instance, three multifunctional peptides exhibiting antibacterial, anti-angiotensin converting enzyme (anti-ACE) and anti-dipeptidyl peptidase IV (anti-DPP-IV) activities have been identified from fish gelatin hydrolysates [11]. In addition, three bifunctional peptides exhibiting anti-ACE and antioxidant activities were identified from egg white hydrolysate [12]. Meanwhile, 10 bifunctional peptides with anti-DPP-IV and antiACE activities in vitro were identified from egg white ovalbumin [13]. Multifunctional peptides are preferable to single-function peptides. The formers are potentially more versatile, allowing the modulation of multiple in vivo pathways and thus imparting multiple health benefits [14]. Such multifunctionality is particularly relevant in the context of relatively complex disorders. An example would be that patients with type II diabetes also often experience hypertension [15]. Zhang et al. [12] proposed that in light of the multifactorial nature of the pathogenesis of hypertension, a bifunctional peptide with concurrent anti-ACE and antioxidant effects may have a better therapeutic effect than a single-function anti-ACE peptide.

Housefly larvae (HFL) have emerged as a potential source of bioactive peptides and proteins only in recent years. By contrast, their significance as a sustainable and alternative source of proteins for animal feed production is well-recognized. Generally, proteins of HFL and other insects are regarded as a promising solution to the increasing global demand for proteins for human food and animal feed production. Crickets and mealworms, for example, are already being used commercially in human food production. By contrast, at present, HFL is mainly used for animal feed production [16-18]. Notably, several studies have pointed to the health-promoting potential of HFL proteins and peptides. For example, two studies have reported the antioxidant activities of HFL protein hydrolysates [19, 20]. A protein-rich HFL extract was found to exert liver- and pancreas-protective activities in the type 2 diabetic rat model, giving no signs of sub-chronic toxicity [21]. Endothelial dysfunction is a key factor in vascular disease. In relation to this, HFL polypeptide extract inhibited the dysfunction of human umbilical vein endothelial cells when challenged by inflammatory cells [22].

The current understanding of the health benefits of HFL peptides in humans is far from comprehensive. Bioinformatic or in silico research strategies can be adopted to expedite the exploration of such information. In silico tools encompassing peptide databases, bioactivity prediction servers, and molecular docking software have been frequently used in bioactive peptide research in recent years. The BIOPEP-UWM database [23], for example, has been used in some studies to screen for potential protease treatments for the generation of bioactive protein hydrolysates. It has also been used to predict and compare the bioactive peptides that could be generated from dietary proteins $[24,25]$. While molecular docking tools have been adopted in docking-based screening for bioactive peptides in some studies, others have also used the tools to elucidate the mechanisms of intermolecular interactions between bioactive 
peptides and their protein targets [26, 27]. Generally, the cost- and time-effectiveness of the in silico approach has driven their popularity in bioactive peptide research [28]. At present, the number of bioactive peptides identified from HFL proteins is still limited. The fate of HFL proteins following human GI digestion is also unknown. Thus, in this study, we have adopted an in silico approach to unravel multifunctional bioactive peptides that may be generated from HFL proteins following in silico GI digestion. The discovery of such peptides, although theoretical, could offer preliminary evidence, serving as the foundation for future work to investigate the health benefits of HFL-derived peptides in the context of the application of HFL proteins for human consumption.

\section{Materials and Methods}

\subsection{In silico GI Digestion.}

Figure 1 shows the overall strategy adopted in this computational study to discover potential multifunctional peptides from the major HFL proteins following degradation by GI proteases. The sequences of the eight major proteins, as previously reported [29], were downloaded from the UniProtKB database (https://www.uniprot.org/) [30] (access date: 21 May 2021). In silico GI digestion of the eight proteins was performed by using the "enzyme(s) action" tool on the BIOPEP-UWM server (http://www.uwm.edu.pl/biochemia/index.php/en/biopep) [23] (access date: 22-24 May 2021). GI digestion was simulated using pepsin, trypsin, and chymotrypsin A, as previously described [27]. All bioactive peptides resulting from the in silico GI digestion were recorded. The peptides were subsequently divided into different single- and multi-function groups.

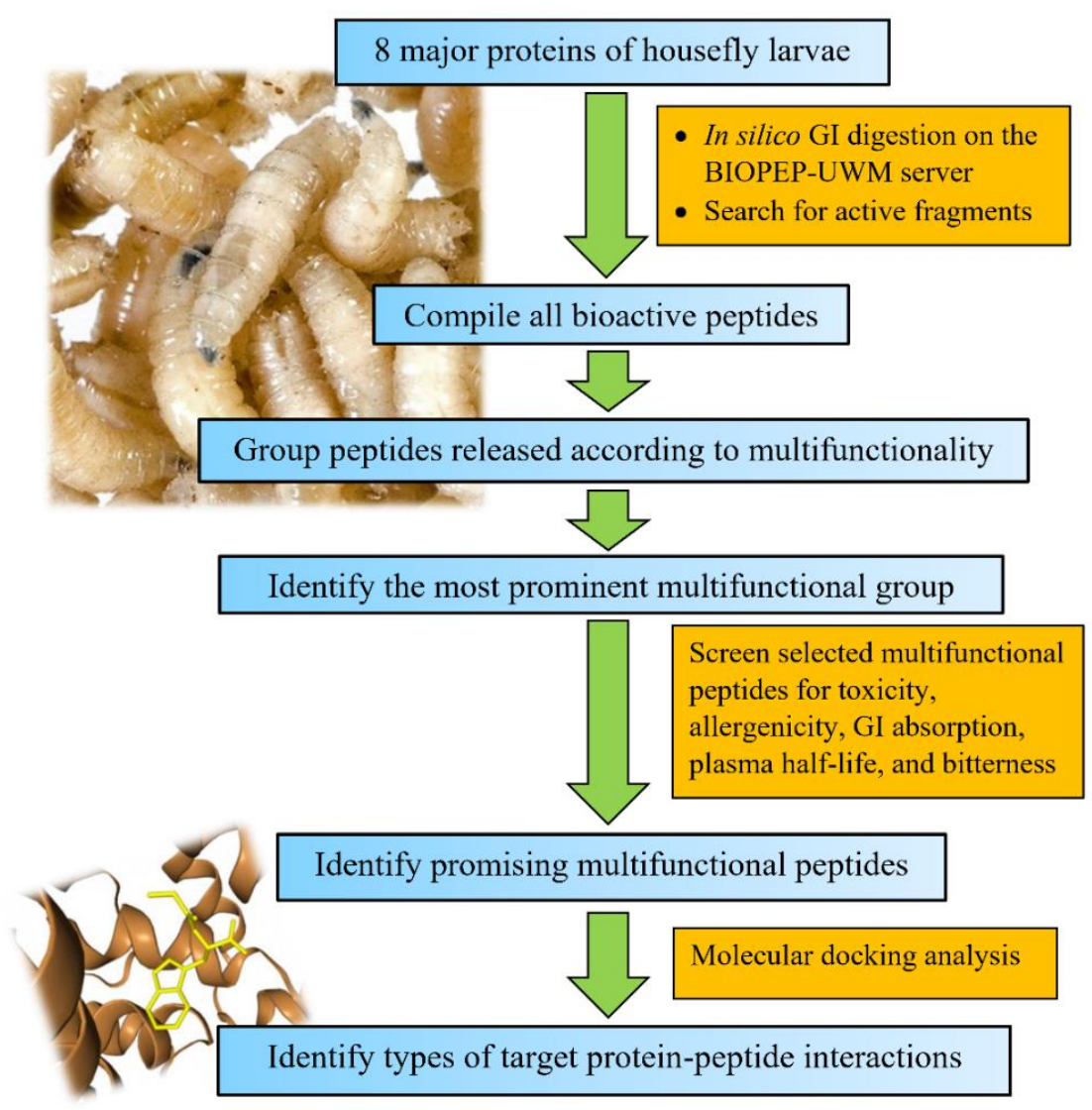

Figure 1. Overview of the study. 
2.2. Screening for toxicity, allergenicity, GI absorption, plasma half-life, and bitterness.

The multifunctional group with the largest number of peptides was screened for toxicity with ToxinPred (https://webs.iiitd.edu.in/raghava/toxinpred/index.html) [31]. The resultant non-toxic peptides were screened for allergenicity using AllerTOP v.2.0 (https://www.ddgpharmfac.net/AllerTOP/) [32]. Peptide sequences predicted as "Non-toxin" and "Probable Non-Allergen" were converted into the Simplified Molecular Input Line Entry System (SMILES) format by using the "SMILES" tool on BIOPEP-UWM [23] and then submitted to SwissADME (http://www.swissadme.ch/) [33] to predict for GI absorption. The plasma halflife of the peptides was predicted by using the PlifePred web server (http://webs.iiitd.edu.in//raghava/plifepred/) [34]. Bitterness was predicted by using the "profiles of sensory activity" tool on BIOPEP-UWM [35]. The aforementioned web tools were accessed between 25 and 30 May 2021.

\subsection{Molecular docking analysis.}

The docking of selected peptides onto two target proteins was carried out with HPEPDOCK (http://huanglab.phys.hust.edu.cn/hpepdock/) [36] (access date: 2 June 2021). Two crystal structures from the RCSB Protein Data Bank (https://www.rcsb.org/) [37], namely human ACE complexed with bradykinin potentiating peptide b (PDB ID: 4APJ) [38] and human DPP-IV complexed with diprotin A (PDB ID: 1WCY) [39], were used. The docking of peptides onto ACE and DPP-IV was performed by submitting the peptide sequences in the FASTA format as peptide input. The top (most negative) docking scores for the peptides were tabulated. BIOVIA Discovery Studio Visualizer (BIOVIA, Dassault Systèmes, BIOVIA Discovery Studio Visualizer, Version 20.1.0.192, San Diego: Dassault Systèmes, 2020) and ProteinsPlus web service (https://proteins.plus) [40, 41] were used for the visualization of the 3D structures of docked models. Intermolecular interactions between a peptide and a target protein were visualized and analyzed using LigPlot+ v.2.2 [42, 43].

\section{Results and Discussion}

In silico GI digestion of eight major HFL proteins generated a total of 783 peptide fragments (Table 1), ranging from 2 to 18 residues (data not shown). Generally, more peptides were released from the proteins of greater molecular masses and peptide length. In this study, catalase $(56.7 \mathrm{kDa})$ released the largest number of peptides $(25 \%)$, about 4.5 -fold more than those released from superoxide dismutase $[\mathrm{Cu}-\mathrm{Zn}](15.6 \mathrm{kDa})$. This observation reflects a greater number of pepsin, trypsin, and chymotrypsin cleavage sites in the protein sequence of catalase than in superoxide dismutase $[\mathrm{Cu}-\mathrm{Zn}]$. Our observation also agrees with a previous report that patatins, which are about 1.8-fold larger than sporamins in mass, released about 2fold more peptide fragments than did sporamins, when both were digested in silico on the BIOPEP-UWM server [44].

Table 1. Major HFL proteins and the number of peptides released from them by in silico GI digestion.

\begin{tabular}{l|c|c|c|c}
\multicolumn{1}{c|}{ Protein } & UniProt ID & $\begin{array}{c}\text { Number of } \\
\text { residues }\end{array}$ & $\begin{array}{c}\text { Molecular } \\
\text { mass (kDa) }\end{array}$ & $\begin{array}{c}\text { Number of peptides } \\
\text { released }\end{array}$ \\
\hline Catalase & T1PCG9 & 505 & 56.7 & 197 \\
\hline Glutathione reductase family member & P91884 & 495 & 53.4 & 166 \\
\hline Superoxide dismutase & G3GJ67 & 214 & 24.2 & 92 \\
\hline Ferritin & T1PLJ3 & 205 & 23.1 & 85 \\
\hline AhpC/TSA family & T1PEX1 & 220 & 24.9 & 82 \\
\hline Antifungal peptide-1 & G9B2K0 & 193 & 21.2 & 72 \\
\hline tps:/biointerfaceresearch.com/ & & & & 4932
\end{tabular}




\begin{tabular}{l|c|c|c|c}
\multicolumn{1}{c|}{ Protein } & UniProt ID & $\begin{array}{c}\text { Number of } \\
\text { residues }\end{array}$ & $\begin{array}{c}\text { Molecular } \\
\text { mass (kDa) }\end{array}$ & $\begin{array}{c}\text { Number of peptides } \\
\text { released }\end{array}$ \\
\hline Cytochrome c & T1PF88 & 108 & 11.7 & 45 \\
\hline Superoxide dismutase [Cu-Zn] & Q6SCL6 & 153 & 15.6 & 44 \\
\hline Total & & & & 783
\end{tabular}

Our analysis of the 783 peptides (Table 1) by using the BIOPEP-UWM server resulted in a collection of 243 peptides exhibiting 13 types of bioactivities (Table 2). Most of the bioactive peptides (94\%) are dipeptides (data not shown). Each of the eight HFL proteins could release anti-DPP-IV, anti-ACE, and antioxidant peptides. By contrast, peptides with antiamnestic and hypolipidemic activities and those capable of stimulating the release of vasoactive substances were rare; only one peptide sequence was detected for each bioactivity type. Overall, $47 \%$ of the bioactive peptides detected were anti-DPP-IV peptides, whereas 33\% were anti-ACE peptides. In line with our findings, in silico proteolysis of fish-roe-derived vitellogenin on the BIOPEP-UWM server revealed that anti-DPP-IV and anti-ACE peptides comprised most of the bioactive peptides detected [45]. Furthermore, in silico investigation on nine tomato seed proteins also found drastically greater frequencies of anti-DPP-IV and antiACE peptides compared to antioxidant peptides [46]. Our observations and those of others could be attributed to the enrichment of the BIOPEP-UWM database with anti-DPP-IV and anti-ACE peptides. Among the 4325 peptides deposited in the database, about 427 and 1051 of them were anti-DPP-IV and anti-ACE peptides, respectively (access date: 03 July 2021) [23]. In this study, catalase stood out from the rest as it released the largest number of bioactive peptides (28\%), following in silico GI digestion (Table 2). Thus, future research could focus on the catalase protein by adopting a targeted approach to discover bioactive peptides from selected HFL proteins following GI digestion or other proteolytic treatments.

Table 2. Bioactive peptides released from HFL proteins by in silico GI digestion.

\begin{tabular}{|c|c|c|c|c|c|c|c|c|c|}
\hline & \multicolumn{9}{|c|}{ Protein } \\
\hline Bioactivity & $\frac{\mathbb{J}}{\frac{\Xi}{\pi}}$ & 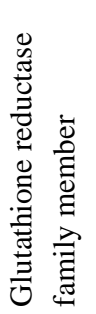 & 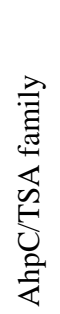 & 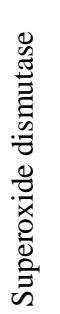 & 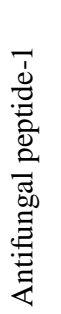 & 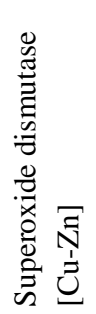 & 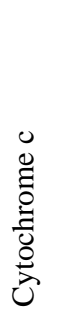 & : & 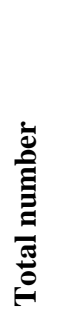 \\
\hline Anti-DPP-IV & 32 & 23 & 15 & 16 & 10 & 9 & 5 & 5 & 115 \\
\hline Anti-ACE & 20 & 22 & 9 & 6 & 9 & 6 & 7 & 2 & 81 \\
\hline Antioxidant & 4 & 1 & 2 & 2 & 1 & 1 & 1 & 2 & 14 \\
\hline Anti-DPP-III & 5 & 3 & 2 & 0 & 0 & 1 & 0 & 0 & 11 \\
\hline Anti-renin & 4 & 0 & 0 & 0 & 0 & 1 & 0 & 0 & 5 \\
\hline Stimulating glucose uptake & 2 & 2 & 0 & 0 & 0 & 0 & 0 & 0 & 4 \\
\hline Regulating ion flow & 0 & 3 & 0 & 1 & 0 & 0 & 0 & 0 & 4 \\
\hline Anti-alpha-glucosidase & 1 & 0 & 0 & 0 & 1 & 0 & 0 & 0 & 2 \\
\hline Anti-CaMPDE $^{\mathrm{a}}$ & 1 & 0 & 0 & 0 & 0 & 1 & 0 & 0 & 2 \\
\hline Anti-inflammatory & 0 & 0 & 1 & 1 & 0 & 0 & 0 & 0 & 2 \\
\hline Anti-amnestic & 0 & 0 & 0 & 1 & 0 & 0 & 0 & 0 & 1 \\
\hline Hypolipidemic & 0 & 0 & 0 & 0 & 0 & 1 & 0 & 0 & 1 \\
\hline Stimulating vasoactive substance release & 0 & 0 & 0 & 1 & 0 & 0 & 0 & 0 & 1 \\
\hline Number of bioactive peptides released & 69 & 54 & 29 & 28 & 21 & 20 & 13 & 9 & 243 \\
\hline
\end{tabular}

To facilitate the discovery of multifunctional peptides, the bioactive peptides reported in Table 2 were further divided into monofunctional peptides and multifunctional peptides, as 
shown in Table 3. A total set of 92 monofunctional peptides exhibiting anti-DPP-IV, anti-ACE, antioxidant or anti-DPP-III activities was detected. The other nine types of bioactivities were found only in multifunctional peptides. Among the 115 anti-DPP-IV peptides (Table 2), 56 were found as multifunctional peptides, concurrently exhibiting anti-DPP-IV and at least one other bioactivity (Table 3). The 32 bifunctional peptides with anti-DPP-IV and anti-ACE activities are the most prominent among the multifunctional groups. The bifunctional antiDPP-IV + anti-ACE peptides consist of only dipeptides (data not shown). Unlike the anti-DPPIV + anti-ACE peptides, not more than 5 peptide sequences were detected for the other multifunctional groups. Thus, our subsequent in silico and molecular docking analyses focused on the bifunctional anti-DPP-IV + anti-ACE peptides.

Table 3. Single- and multi-function bioactive peptides released from HFL proteins by in silico GI digestion.

\begin{tabular}{|c|c|c|}
\hline $\begin{array}{l}\text { Type of bioactive } \\
\text { peptides }\end{array}$ & Bioactivity & Number of peptides \\
\hline \multirow[t]{4}{*}{ Monofunctional } & Anti-DPP-IV & 59 \\
\hline & Anti-ACE & 26 \\
\hline & Antioxidant & 6 \\
\hline & Anti-DPP-III & 1 \\
\hline \multirow[t]{7}{*}{ Bifunctional } & Anti-DPP-IV + anti-ACE & 32 \\
\hline & Anti-ACE + regulating ion flow & 4 \\
\hline & Anti-DPP-IV + glucose uptake stimulating & 3 \\
\hline & Anti-DPP-IV + anti-DPP-III & 2 \\
\hline & Anti-DPP-IV + anti-inflammatory & 2 \\
\hline & Anti-ACE + antioxidant & 1 \\
\hline & Anti-ACE + anti-DPP-III & 1 \\
\hline \multirow[t]{5}{*}{ Trifunctional } & Anti-DPP-IV + anti-ACE + anti-DPP-III & 5 \\
\hline & Anti-DPP-IV + anti-ACE + antioxidant & 4 \\
\hline & Anti-DPP-IV + anti-ACE + anti-renin & 1 \\
\hline & Anti-DPP-IV + anti-ACE + stimulating glucose uptake & 1 \\
\hline & Anti-DPP-IV + stimulating vasoactive substance release + anti-amnestic & 1 \\
\hline \multirow[t]{3}{*}{ Tetrafunctional } & Anti-DPP-IV + anti-ACE + antioxidant + anti-alpha-glucosidase & 2 \\
\hline & Anti-DPP-IV + anti-ACE + anti-DPP-III + anti-renin & 2 \\
\hline & Anti-ACE + anti-renin + anti-CaMPDE + hypolipidemic & 1 \\
\hline Pentafunctional & Anti-DPP-IV + anti-ACE + antioxidant + anti-renin + anti-CaMPDE ${ }^{\mathrm{a}}$ & 1 \\
\hline
\end{tabular}

Screening of the 32 anti-DPP-IV + anti-ACE dipeptides (Table 3) revealed five that were predicted to possess desirable qualities, namely non-toxic, non-allergenic, and high GI absorption (Table 4). The five dipeptides are not unique to HFL, but also released by other dietary proteins following proteolysis. For example, GY and VF were also released by in silico GI digestion of oat globulins [47]. PH was identified from anti-ACE milk hydrolysates [48], whereas VF is a competitive anti-ACE inhibitor identified from a sardine muscle hydrolysate [49]. GW, GY, and AF were anti-ACE peptides identified from fermented soybean seasoning, which was shown to have antihypertensive effects in animal models [50].

Table 4. Toxicity, allergenicity, GI absorption, plasma half-life, and bitterness predicted five bifunctional antiDPP-IV and anti-ACE peptides.

\begin{tabular}{c|c|c|c|c|c} 
Peptide & Toxicity & Allergenicity & GI absorption & Plasma half-life (seconds) & Bitterness \\
\hline AF & Non-toxin & Probable non-allergen & High & 834.81 & Bitter \\
\hline GW & Non-toxin & Probable non-allergen & High & 834.81 & Non-bitter \\
\hline GY & Non-toxin & Probable non-allergen & High & 834.71 & Bitter \\
\hline PH & Non-toxin & Probable non-allergen & High & 834.81 & Non-bitter \\
\hline VF & Non-toxin & Probable non-allergen & High & 834.81 & Bitter
\end{tabular}


GW and VF were also purified from katsuobushi and validated for anti-DPP-IV activities in vitro [51].

Gupta, et al. [31] suggested that non-toxin peptides usually contain valine, threonine, arginine, glutamine, methionine, leucine, lysine, isoleucine, phenylalanine, and alanine. This description matches the dipeptides $\mathrm{AF}$ and VF in this study. Besides toxicity, allergenicity should also be considered when evaluating the potential of bioactive peptides as future food ingredients or therapeutic agents. This ensures that the peptides could exert their healthpromoting or disease-preventing effects when consumed, without causing undesirable immunological responses or harmful side effects [32]. Furthermore, bioactive peptides proposed for applications as food ingredients or therapeutic agents should have high bioavailability. Bioactive peptides can only modify physiological pathways if they can reach the in vivo targets after being absorbed through the intestinal wall [52]. In this context, the five bifunctional peptides in Table 4 are promising as they were predicted to show high GI absorption, in addition to being resistant to degradation by GI enzymes. The latter is implicated as the five dipeptides were produced following in silico digestion by GI proteases. The uptake of dipeptides into the mammalian small-intestinal enterocytes has been well-established in the literature, which is facilitated by a PepT1 $\mathrm{H}^{+}$/peptide co-transporter. The co-transporter is known to have a very broad substrate specificity encompassing about 400 dipeptides [53]. Thus, the high GI absorption predicted for the five bifunctional peptides in this study is anticipated.

Among other factors, the expression of in vivo bioactivity requires a peptide to be stable in blood [34, 54]. In this study, the five bifunctional dipeptides in Table 4 did not differ in their predicted plasma half-life values. This implies that they are likely similarly susceptible to plasma peptidases during systemic circulation. Mathur et al. [34] reported that peptides enriched in aromatic and neutral residues are more likely to have a shorter half-life than other peptides; the five bifunctional dipeptides we found in this study comprise those amino acids. PlifePred predicted that glutathione, a natural tripeptide, had a plasma half-life about 9-fold longer than the five bifunctional dipeptides (data not shown). The uncommon first peptide linkage could account for this in glutathione that involves a gamma-carboxyl group in its formation. In fact, structural modification strategies, such as cyclization and N- or C-terminal acetylation/amidation, have been proposed to enhance the in vivo half-life of bioactive peptides [54]. Such strategies would be useful in the future to improve the bioavailability of the five bifunctional dipeptides.

AF, GY, and VF were predicted to be bitter (Table 4). As reported by Iwaniak et al. [55], bitterness is associated with the presence of branched-chain amino acids (such as valine) and aromatic amino acids (such as phenylalanine and tyrosine) in the composition of a peptide. The significance of phenylalanine and tyrosine in imparting bitterness could be attributed to their ability to bind to the bitter taste receptors of the gustation cells [56]. In general, although the five bifunctional peptides could be potentially developed into dual-function anti-DPP-IV and anti-ACE therapeutics in the future, the non-bitter GW and $\mathrm{PH}$ would be preferable when considering the formulation of functional food from these five peptides. The integration of nonbitter peptides would be less likely to adversely affect the taste profile of orally-taken products, hence more likely to be acceptable to consumers.

To understand the mechanisms of the five bifunctional peptides as DPP-IV and ACE inhibitors, we performed molecular docking analyses on the peptides. The empirical evidence of the anti-DPP-IV and anti-ACE activities of the five peptides was reported [48-50, 57, 58]. 
However, to the best of our knowledge, systematic docking analysis of the five dipeptides on DPP-IV and ACE has not been reported in the same study. Molecular docking of VF and AF on ACE $[59,60]$ and that of GW on DPP-IV [61] was reported. However, except for VF, details on the interactions of the five bifunctional peptides with ACE and DPP-IV are still unavailable.

The active site of DPP-IV comprises the catalytic triad (Ser630, Asn710, and His740), the hydrophobic S1 pocket (Tyr631, Val656, Trp659, Tyr662, Tyr666, Val711), and the S2 pocket (Arg125, Glu205, Glu206, Ser209, Phe357, Arg358) [62]. Our molecular docking simulations revealed that the five bifunctional dipeptides could bind to the catalytic triad and the two pockets mainly through hydrogen bonds and hydrophobic interactions (Table 5). GW was predicted to have the most negative docking scores among the five dipeptides, implying the most stable binding to DPP-IV [63]. A graphical representation of the intermolecular interactions between GW and DPP-IV is shown in Figure 2.

Table 5. Docking scores of bifunctional anti-DPP-IV and anti-ACE peptides and their intermolecular

\begin{tabular}{|c|c|c|c|c|}
\hline & & \multirow{2}{*}{$\begin{array}{l}\text { Docking } \\
\text { score }\end{array}$} & \multicolumn{2}{|r|}{ Interaction with residues of DPP-IV ${ }^{\mathrm{a}}$} \\
\hline & & & Hydrogen bond & $\begin{array}{l}\text { Hydrophobic interaction } \\
\end{array}$ \\
\hline \multirow{5}{*}{ 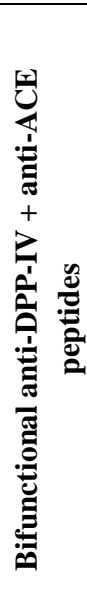 } & GW & -141.824 & $\begin{array}{l}\text { Arg125(2), Glu205, } \\
\underline{\text { Glu206 }}\end{array}$ & $\begin{array}{l}\text { Arg125, Glu205, Glu206, Tyr547, Ser630, Tyr631, Val656, } \\
\underline{\text { Trp659 }}, \underline{\text { Tyr662 }}, \underline{\text { Tyr666 }}, \text { Asn710, Val711, His740 }\end{array}$ \\
\hline & $\mathrm{PH}$ & -132.725 & $\underline{\operatorname{Arg} 125}, \underline{\text { Tyr662 }}$ & $\begin{array}{l}\underline{\text { Arg125 }}, \underline{\text { Glu205 }}, \underline{\text { Glu206}}, \text { Tyr547, Ser630, Tyr631, Val656, } \\
\underline{\text { Trp659 }}, \underline{\text { Tyr662 }}, \underline{\text { Tyr666 }}, \text { His740 }\end{array}$ \\
\hline & $\mathrm{VF}$ & -128.224 & $\begin{array}{l}\text { Arg125(2), Glu205, } \\
\text { Glu206, His740 }\end{array}$ & $\begin{array}{l}\underline{\text { Arg125 }}, \underline{\text { Glu205 }}, \underline{\text { Glu206, Tyr547, Ser630, Tyr631, Val656, }}, \underline{\text { Trp659 }}, \underline{\text { Tyr662 }}, \underline{\text { Tyr666 }}, \text { Asn710, Val711, His740 }\end{array}$ \\
\hline & GY & -122.504 & $\underline{\text { Tyr662 }}$ & $\begin{array}{l}\text { Arg125, Glu205, Glu206, Tyr547, Ser630, Tyr631, Val656, } \\
\text { Trp659, Tyr662, Tyr666, Asn710, Val711, His740 }\end{array}$ \\
\hline & $\mathrm{AF}$ & -112.008 & $\begin{array}{l}\text { Arg125, Tyr547, } \\
\text { His740 }\end{array}$ & $\begin{array}{l}\underline{\operatorname{Arg} 125}, \underline{\text { Glu205}}, \underline{\text { Glu206}}, \text { Tyr547, Ser630, Tyr631, Val656, } \\
\underline{\text { Trp659, }}, \underline{\text { Tyr662 }}, \underline{\text { Tyr666 }}, \text { Asn710, Val711 }, \text { His740 }\end{array}$ \\
\hline \multirow{3}{*}{ 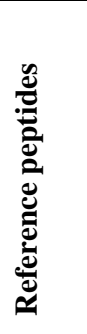 } & $\mathrm{CF}$ & -115.889 & $\underline{\operatorname{Arg} 125(2)}, \underline{\text { Glu206 }}$ & 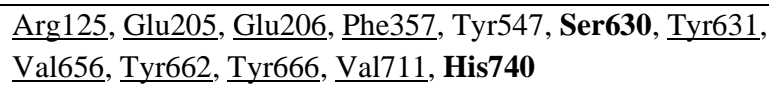 \\
\hline & KM & -103.657 & $\frac{\operatorname{Arg} 125}{\text { Glu206, Glu205, }}, \underline{\text { Ser209 }}$ & 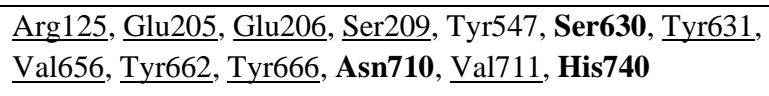 \\
\hline & $\mathrm{AM}$ & -93.654 & $\underline{\operatorname{Arg} 125}, \underline{\text { Glu206 }}$ & $\begin{array}{l}\text { Arg125, Glu205, Glu206, Tyr547, Ser630, Tyr631, Val656, } \\
\text { Tyr662, Tyr666, Asn710, Val711, His740 }\end{array}$ \\
\hline
\end{tabular}

${ }^{a}$ Number in brackets indicates the number of hydrogen bonds formed with the same DPP-IV residue. Residues in bold indicate catalytic triad residues of DPP-IV. Other residues in the active site of DPP-IV are underlined.

As shown in Table 5, except for PH, the bifunctional peptides were predicted to bind to all three residues in the catalytic triad by hydrophobic interactions. VF and AF could also bind to His740 of the catalytic triad by means of the hydrogen bond. Our result suggests that hydrogen bonds play a greater role in binding the peptides to the S2 pocket than to the $\mathrm{S} 1$ pocket of DPP-IV. Only GY and PH could hydrogen-bond to residue in the S1 pocket (Tyr662). By contrast, except for GY, the bifunctional peptides could hydrogen-bond to at least one of the residues in the S2 pocket, mainly with Arg125, Glu205, and Glu206. This is desirable as binding to Glu205 and Glu206 in the S2 pockets is believed to play an important role in stabilizing the binding of inhibitors to DPP-IV [64]. 


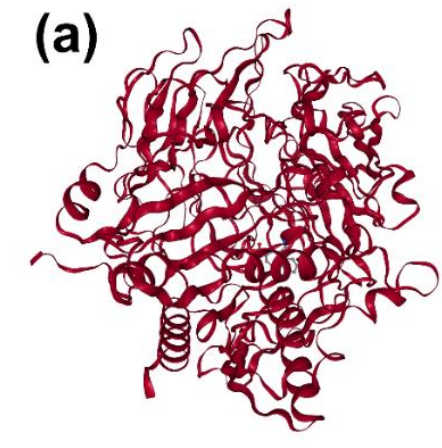

(b)

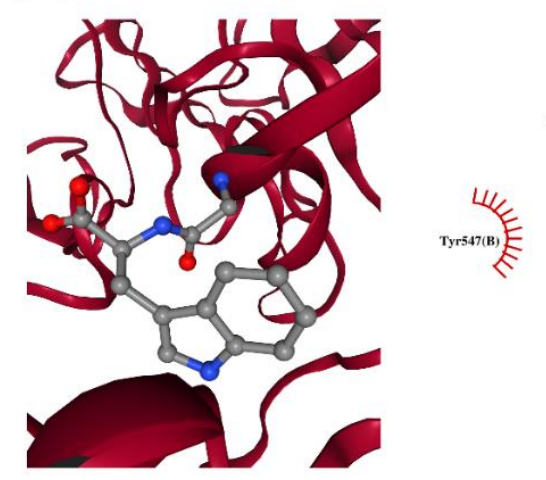

(c)

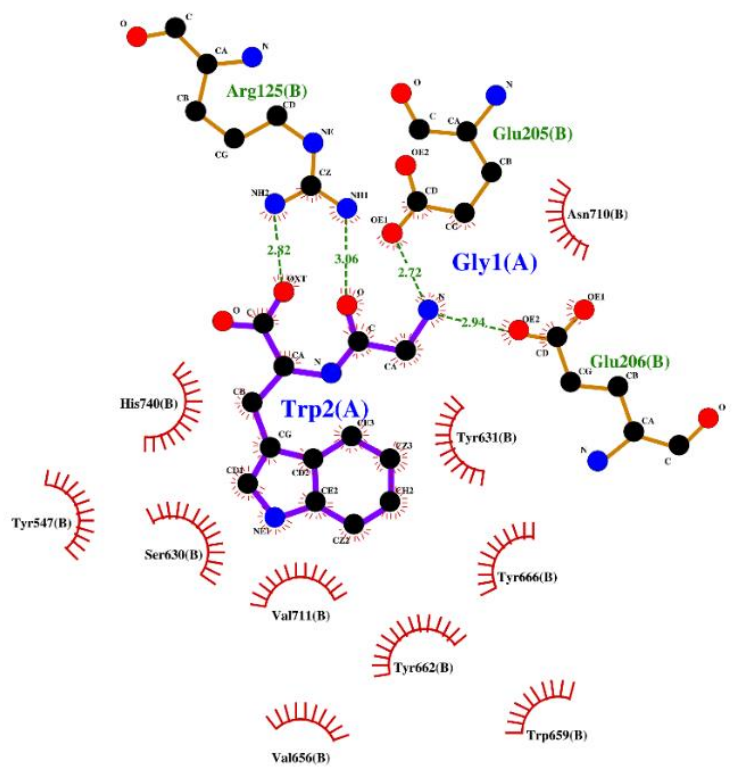

Figure 2. The GW-DPP-IV docked model presented in 3D $(\mathbf{A}, \mathbf{B})$ and $2 \mathrm{D}(\mathbf{C})$ diagrams. The protein is shown in the cartoon in maroon; the peptide is presented in a ball-and-stick style. In the 2D diagram $(\mathbf{C})$, the hydrophobic bonds and hydrogen bonds are displayed in red spoked arcs, and green dashed lines, respectively.

GW has a more negative docking score than VF, suggesting that GW may form a more stable binding to DPP-IV compared with VF. The greater binding stability of GW to DPP-IV corroborates with the report of the stronger in vitro anti-DPP-IV activity of GW, relative to VF [51]. Meanwhile, VF could form almost the same interactions with DPP-IV as could GW, except for one additional hydrogen bond (with catalytic residue His740) involving VF, but not GW (Table 5). Our results imply that the additional hydrogen bond with a catalytic residue would neither contribute to greater binding stability between a dipeptide and DPP-IV, nor enhance the anti-DPP-IV activity of a dipeptide. A logical hypothesis, in this case, is that the specific identity of the peptide residue forming a hydrogen bond and/or hydrophobic interaction with DPP-IV would influence the contribution of that interaction to the overall docking stability.

$\mathrm{CF}, \mathrm{KM}$, and AM are three reference dipeptides we adopted, whose anti-DPP-IV and anti-ACE activities have been verified empirically [13]. Our LigPlot analysis revealed that GW and VF resemble KM in that all three of them could interact with Arg125, Glu205, and Glu206 in the S2 pocket via hydrogen bonds and hydrophobic interactions. Furthermore, the three of them can form hydrophobic interactions with the catalytic triad of DPP-IV. Based on the comparison of docking scores, four HFL-derived dipeptides (GW, PH, VF, and GY) apparently could bind to DPP-IV more stably than the three reference peptides. However, at this point, it is uncertain whether the four HFL peptides would be more potent than the three refence peptides. GW, which could bind more stably to DPP-IV relative to VF in this study, was previously reported to have greater anti-DPP-IV activity than VF [51]. However, the binding stability of the three reference peptides in this study does not correlate with the report that their relative anti-DPP-IV activities, in descending order, are $\mathrm{KM}>\mathrm{AM}>\mathrm{CF}$ [13]. In short, binding stability is apparently not the main factor determining the anti-DPP-IV activity of all 
dipeptides. In the case of the three reference peptides we adopted, the ability of KM and AM to bind to all three residues of the catalytic triad of DPP-IV might have contributed to their stronger activities relative to $\mathrm{CF}$.

The active site of ACE comprises the inhibitor binding site (His383, His387, and Glu411), S1 pocket (Ala354, Glu384, and Tyr523), S2 pocket (Gln281, His353, Lys511, His513, and Tyr520), and S1' (Glu162) [65]. Unlike our results for docking on DPP-IV, only two bifunctional dipeptides GW and VF, could bind to residues in the active site pockets (Table 6). GW and VF were both predicted to hydrogen-bond to residues in the $\mathrm{S} 2$ pocket. By means of hydrophobic interactions, both GW and VF could bind to S1 and S2 pockets, but only VF could bind to the S1' pocket. As in docking to DPP-IV (Table 5), the docking of GW to ACE also produced the most negative score, indicating the most stable binding to the active site pockets. Notably, GW is the only bifunctional dipeptide that was predicted to bind to all three residues in the ACE inhibitor binding site. Figure 3 shows GW binding to the active site of ACE through hydrogen bonds and hydrophobic interactions.

Table 6. Docking scores of bifunctional anti-DPP-IV and anti-ACE peptides and their intermolecular interactions with ACE.

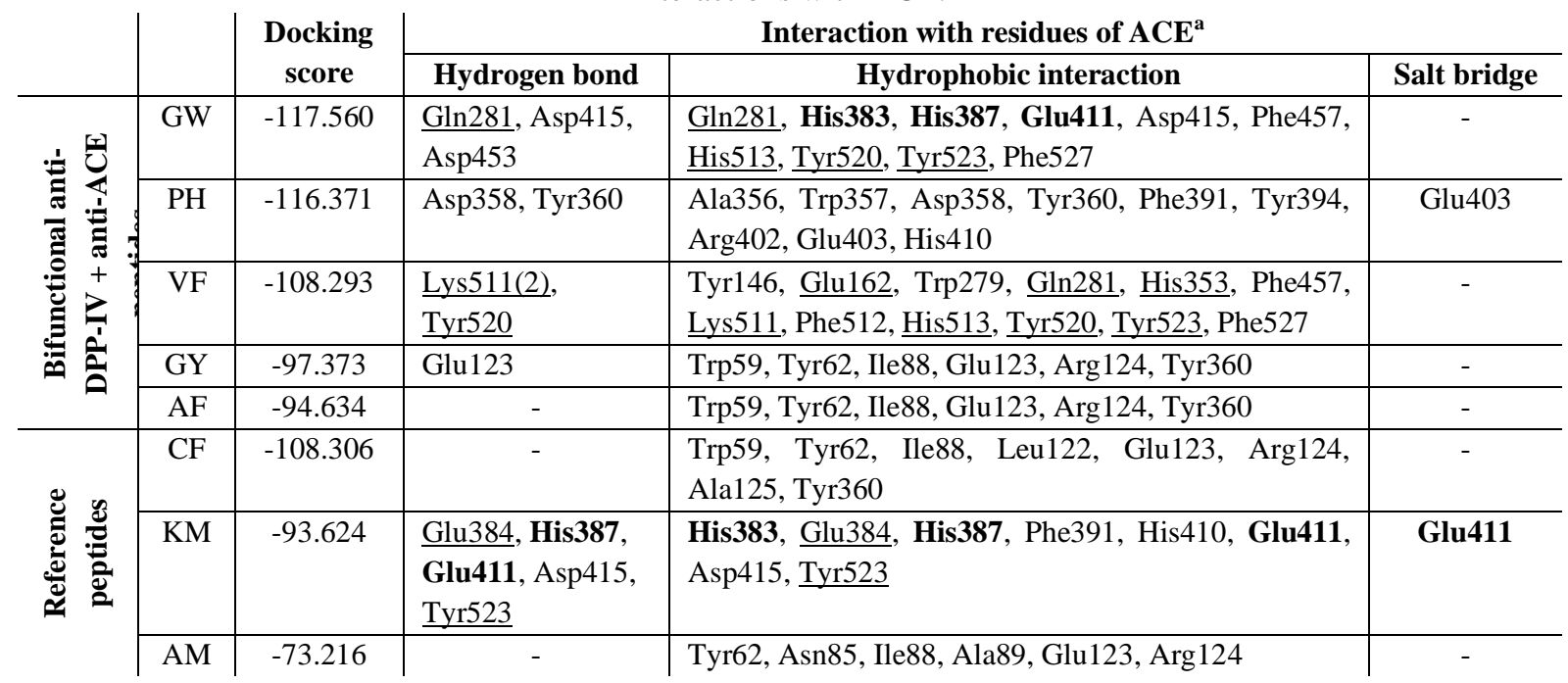

${ }^{a}$ Number in brackets indicates the number of hydrogen bonds formed with the same ACE residue. Residues in the inhibitor binding site of ACE are listed in bold, whereas other residues in the active site pockets of ACE are underlined.

The empirical evidence for the anti-DPP-IV and anti-ACE activities of the five bifunctional HFL peptides in this study were previously reported [48-50, 57, 58]. Nevertheless, their modes of ACE inhibition are largely unknown, except for VF, which was reported as a competitive ACE inhibitor [49]. ACE inhibitory peptides that bind to a site on ACE other than its active site are non-competitive inhibitors [65]. Thus based on their interactions with ACE (Table 6), GW possibly also acts as a competitive inhibitor, like VF. By contrast, PH, GY, and AF could be potential non-competitive inhibitors. Based on the comparison of docking scores, GW and PH may bind more stably to ACE when compared with all three reference peptides. Interestingly, the relative docking scores of the three reference peptides also correlate with their relative anti-ACE activities, as reported by Mohd and Gan [13].

Moreover, $\mathrm{CF}$ is potentially a non-competitive inhibitor. It was predicted to bind to residues outside the active site pockets, which contrasts with the binding interactions formed by KM, a potential competitive inhibitor. Furthermore, we also found that $\mathrm{PH}$, which could not bind to the active site pockets of ACE, was predicted to form more stable binding to ACE 
relative to VF. Similarly, among the reference peptides, CF, which could not bind to the active site pockets of ACE, was predicted to bind more stably to ACE, when compared with KM. KM is the only reference peptide that could bind to the $\mathrm{S} 1$ active site pocket and the inhibitor binding site of ACE (Table 6).

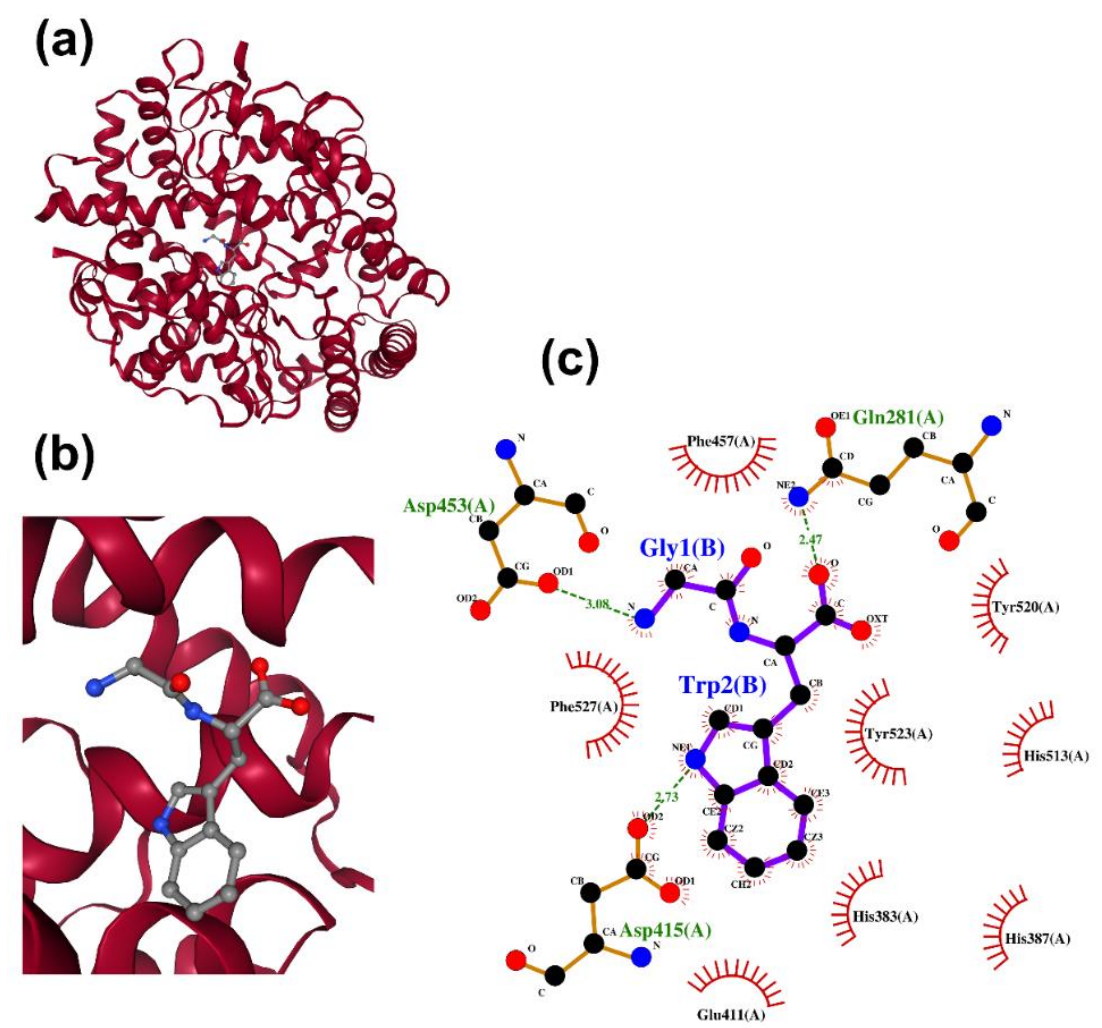

Figure 3. The ACE-GW docked model presented in 3D (A, B) and 2D (C) diagrams. Descriptions for 2D and 3D diagrams are the same as those in Figure 2.

Taken together, our docking results suggest that all five bifunctional peptides derived from HFL are likely competitive DPP-IV inhibitors, but consist of a mixture of competitive and non-competitive ACE inhibitors; similar observations were made on the three reference peptides we used for comparison.

This being an in silico study has its limitations. For instance, the release of bioactive peptides by in silico GI digestion in this study does not consider factors such as in vivo GI enzyme concentration, temperature, duration, and accessibility of enzyme to the cleavage sites of proteins [66, 67]. Thus, in vitro simulated GI digestion experiments are warranted to confirm the release of the aforementioned bifunctional peptides from HFL proteins. In vitro and/or in vivo validation of the predicted lack of toxicity and allergenicity, high GI absorption, and plasma half-life of the peptides is also inevitable. Notwithstanding, this study has narrowed down the potential peptide candidates to only five, which should make the task more feasible. Going forward, the possibility of synergism between the five bifunctional peptides is an interesting question to address, which could not be investigated with our in silico strategy.

\section{Conclusions}

Five bifunctional anti-DPP-IV + anti-ACE peptides were discovered from major HFL proteins following in silico GI digestion. The five peptides were predicted to be non-toxic and non-allergenic, besides a high probability of GI absorption. Molecular docking simulations point to the five peptides being competitive DPP-IV inhibitors and a mixture of competitive 
and non-competitive ACE inhibitors. Taken together, our study suggests that HFL proteins could be a promising source of bifunctional peptides with antidiabetic and antihypertension potential.

\section{Funding}

This research received no external funding.

\section{Acknowledgments}

None declared.

\section{Conflicts of Interest}

The authors declare no conflict of interest.

\section{References}

1. Chai, T.-T.; Ee, K.-Y.; Kumar, D.T.; Abd Manan, F.; Wong, F.-C. Plant bioactive peptides: current status and prospects towards use on human health. Protein Pept. Lett. 2020, 28, 623-642, https://doi.org/10.2174/0929866527999201211195936.

2. Apostolopoulos, V.; Bojarska, J.; Chai, T.T.; Elnagdy, S.; Kaczmarek, K.; Matsoukas, J.; New, R.; Parang, K.; Lopez, O.P.; Parhiz, H.; Perera, C.O.; Pickholz, M.; Remko, M.; Saviano, M.; Skwarczynski, M.; Tang, Y.; Wolf, W.M.; Yoshiya, T.; Zabrocki, J.; Zielenkiewicz, P.; Alkhazindar, M.; Barriga, V.; Kelaidonis, K.; Sarasia, E.M.; Toth, I. A global review on short peptides: frontiers and perspectives. Molecules 2021, 26, 430, https://doi.org/10.3390/molecules26020430.

3. Wong, F.-C.; Xiao, J.; Wang, S.; Ee, K.-Y.; Chai, T.-T. Advances on the antioxidant peptides from edible plant sources. Trends Food Sci. Technol. 2020, 99, 44-57, https://doi.org/10.1016/j.tifs.2020.02.012.

4. Wong, F.C.; Xiao, J.; Ong, M.G.L.; Pang, M.J.; Wong, S.J.; Teh, L.K.; Chai, T.T. Identification and characterization of antioxidant peptides from hydrolysate of blue-spotted stingray and their stability against thermal, ph and simulated gastrointestinal digestion treatments. Food Chem. 2019, 271, 614-622, https://doi.org/10.1016/j.foodchem.2018.07.206.

5. Quah, Y.; Mohd Ismail, N.I.; Ooi, J.L.S.; Affendi, Y.A.; Abd Manan, F.; Wong, F.C.; Chai, T.T. Identification of novel cytotoxic peptide KENPVLSLVNGMF from marine sponge Xestospongia testudinaria, with characterization of stability in human serum. Int. J. Pept. Res. Ther. 2018, 24, 189-199, https://doi.org/10.1007/s10989-017-9604-6.

6. Quah, Y.; Mohd Ismail, N.I.; Ooi, J.L.S.; Affendi, Y.A.; Abd Manan, F.; Teh, L.K.; Wong, F.C.; Chai, T.T. Purification and identification of novel cytotoxic oligopeptides from soft coral Sarcophyton glaucum. $J$. Zhejiang Univ. Sci. B 2019, 20, 59-70, https://doi.org/10.1631/jzus.B1700586.

7. Chai, T.T.; Soo, Z.Y.; Hsu, K.C.; Li, J.C.; Abd Manan, F.; Wong, F.C. Antioxidant activity of semen cassiae protein hydrolysate: thermal and gastrointestinal stability, peptide identification, and in silico analysis. Mod. Food Sci. Technol. 2019, 35, 38-48, https://doi.org/10.13982/j.mfst.1673-9078.2019.9.004.

8. Mohana Dass, S.; Chai, T.T.; Wong, F.C. Antioxidant and protein protection potentials of fennel seed-derived protein hydrolysates and peptides. Mod. Food Sci. Technol. 2019, 35, 22-49, https://doi.org/10.13982/j.mfst.1673-9078.2019.9.002.

9. Chai, T.T.; Xiao, J.; Mohana Dass, S.; Teoh, J.Y.; Ee, K.Y.; Ng, W.J.; Wong, F.C. Identification of antioxidant peptides derived from tropical jackfruit seed and investigation of the stability profiles. Food Chem. 2021, 340, 127876, https://doi.org/10.1016/j.foodchem.2020.127876.

10. Chai, T.-T.; Law, Y.-C.; Wong, F.-C.; Kim, S.-K. Enzyme-assisted discovery of antioxidant peptides from edible marine invertebrates: a review. Mar. Drugs 2017, 15, 42, https://doi.org/10.3390/MD15020042.

11. Mirzapour-Kouhdasht, A.; Moosavi-Nasab, M.; Lee, C.W.; Yun, H.; Eun, J.B. Structure-function engineering of novel fish gelatin-derived multifunctional peptides using high-resolution peptidomics and bioinformatics. Sci. Rep. 2021, 11, 1-15, https://doi.org/10.1038/s41598-021-86808-9.

12. Zhang, B.; Liu, J.; Liu, C.; Liu, B.; Yu, Y.; Zhang, T. Bifunctional peptides with antioxidant and angiotensinconverting enzyme inhibitory activity in vitro from egg white hydrolysates. J. Food Biochem. 2020, 44, 
e13347, https://doi.org/10.1111/jfbc.13347.

13. Mohd Salim, M.A.S.; Gan, C.Y. Dual-function peptides derived from egg white ovalbumin: bioinformatics identification with validation using in vitro assay. J. Funct. Foods 2020, 64, 103618, https://doi.org/10.1016/j.jff.2019.103618.

14. Daliri, E.B.M.; Oh, D.H.; Lee, B.H. Bioactive Peptides. Foods 2017, 6, 1-21, https://doi.org/10.3390/foods6050032.

15. Boer, I.H. de; Bangalore, S.; Benetos, A.; Davis, A.M.; Michos, E.D.; Muntner, P.; Rossing, P.; Zoungas, S.; Bakris, G. Diabetes and hypertension: a position statement by the American Diabetes Association. Diabetes Care 2017, 40, 1273-1284, https://doi.org/10.2337/DCI17-0026.

16. Khan, S.H. Recent advances in role of insects as alternative protein source in poultry nutrition. J. Appl. Anim. Res. 2018, 46, 1144-1157, https://doi.org/10.1080/09712119.2018.1474743.

17. Dörper, A.; Veldkamp, T.; Dicke, M. Use of black soldier fly and house fly in feed to promote sustainable poultry production. J. Insects as Food Feed 2020, 1-20, https://doi.org/10.3920/jiff2020.0064.

18. Kim, T.-K.; Yong, H.I.; Kim, Y.-B.; Kim, H.-W.; Choi, Y.-S. Edible insects as a protein source: a review of public perception, processing technology, and research trends. Food Sci. Anim. Resour. 2019, 39, 521, https://doi.org/10.5851/KOSFA.2019.E53.

19. Wang, J.; Wang, Y.; Dang, X.; Zheng, X.; Zhang, W. Housefly larvae hydrolysate: orthogonal optimization of hydrolysis, antioxidant activity, amino acid composition and functional properties. BMC Res. Notes 2013, 6, 1-10, https://doi.org/10.1186/1756-0500-6-197.

20. Zhang, H.; Wang, P.; Zhang, A.J.; Li, X.; Zhang, J.H.; Qin, Q.L.; Wu, Y.J. Antioxidant activities of protein hydrolysates obtained from the housefly larvae. Acta Biol. Hung. 2016, 67, 236-246, https://doi.org/10.1556/018.67.2016.3.2.

21. Mei, H.; Xu, J.; He, Y.; Yang, X.; Liu, W.; Tian, W.; Zeng, Y.; Zhu, J. Protein-rich extract of Musca domestica larvae alleviated metabolic disorder in STZ-induced type 2 diabetic rat model via hepatoprotective and pancreatic $\beta$-cell protective activities. J. Biosci. 2018, 43, 969-983, https://doi.org/10.1007/s12038-0189804-z.

22. Chu, F.; Jin, X.; Ma, H.; Lu, X.; Zhu, J. Effect of Musca domestic maggot polypeptide extract on huvec dysfunction induced by early-activated macrophages. Pharm. Biol. 2016, 54, 572-575, https://doi.org/10.3109/13880209.2015.1060506.

23. Minkiewicz, P.; Iwaniak, A.; Darewicz, M. BIOPEP-UWM database of bioactive peptides: current opportunities. Int. J. Mol. Sci. 2019, 20, 5978, https://doi.org/10.3390/ijms20235978.

24. Barati, M.; Javanmardi, F.; Jabbari, M.; Mokari-Yamchi, A.; Farahmand, F.; Eş, I.; Farhadnejad, H.; Davoodi, S.H.; Mousavi Khaneghah, A. An in silico model to predict and estimate digestion-resistant and bioactive peptide content of dairy products: a primarily study of a time-saving and affordable method for practical research purposes. LWT 2020, 130, 109616, https://doi.org/10.1016/J.LWT.2020.109616.

25. Ji, D.; Udenigwe, C.C.; Agyei, D. Antioxidant peptides encrypted in flaxseed proteome: an in silico assessment. Food Sci. Hum. Wellness 2019, 8, 306-314, https://doi.org/10.1016/J.FSHW.2019.08.002.

26. Ong, J.H.; Liang, C.E.; Wong, W.L.; Wong, F.C.; Chai, T.T. Multi-target anti-SARS-CoV-2 peptides from mealworm proteins: an in silico study. Malaysian J. Biochem. Mol. Biol. 2021, 24, 83-91, https://1f1692270328-4af2-99bc-24934f131be8.filesusr.com/ugd/66925b_804c93d9d0fe4852a85099d6e6b9e910.pdf.

27. Wong, F.-C.; Ong, J.-H.; Chai, T.-T. Identification of putative cell-entry-inhibitory peptides against SARSCoV-2 from edible insects: an in silico study. eFood 2020, 1, 357, https://doi.org/10.2991/efood.k.200918.002.

28. Agyei, D.; Tsopmo, A.; Udenigwe, C.C. Bioinformatics and Peptidomics Approaches to the Discovery and Analysis of Food-Derived Bioactive Peptides. Anal. Bioanal. Chem. 2018, 410, 3463-3472, https://doi.org/10.1007/s00216-018-0974-1.

29. Jiao, M.; Chen, L.; He, Y.; Wu, L.; Mei, H. Identification of proteins in housefly (Musca domestica) larvae powder by lc-ms/ms and their potential medical relevance. RSC Adv. 2019, 9, 30545-30555, https://doi.org/10.1039/C9RA05854K.

30. Bateman, A.; Martin, M.-J.; Orchard, S.; Magrane, M.; Agivetova, R.; Ahmad, S.; Alpi, E.; Bowler-Barnett, E.H.; Britto, R.; Bursteinas, B.; Bye-A-Jee, H.; Coetzee, R.; Cukura, A.; Da Silva, A.; Denny, P.; Dogan, T.; Ebenezer, T.; Fan, J.; Castro, L.G.; Garmiri, P.; Georghiou, G.; Gonzales, L.; Hatton-Ellis, E.; Hussein, A.; Ignatchenko, A.; Insana, G.; Ishtiaq, R.; Jokinen, P.; Joshi, V.; Jyothi, D.; Lock, A.; Lopez, R.; Luciani, A.; Luo, J.; Lussi, Y.; MacDougall, A.; Madeira, F.; Mahmoudy, M.; Menchi, M.; Mishra, A.; Moulang, K.; Nightingale, A.; Oliveira, C.S.; Pundir, S.; Qi, G.; Raj, S.; Rice, D.; Lopez, M.R.; Saidi, R.; Sampson, J.; 
Sawford, T.; Speretta, E.; Turner, E.; Tyagi, N.; Vasudev, P.; Volynkin, V.; Warner, K.; Watkins, X.; Zaru, R.; Zellner, H.; Bridge, A.; Poux, S.; Redaschi, N.; Aimo, L.; Argoud-Puy, G.; Auchincloss, A.; Axelsen, K.; Bansal, P.; Baratin, D.; Blatter, M.-C.; Bolleman, J.; Boutet, E.; Breuza, L.; Casals-Casas, C.; de Castro, E.; Echioukh, K.C.; Coudert, E.; Cuche, B.; Doche, M.; Dornevil, D.; Estreicher, A.; Famiglietti, M.L.; Feuermann, M.; Gasteiger, E.; Gehant, S.; Gerritsen, V.; Gos, A.; Gruaz-Gumowski, N.; Hinz, U.; Hulo, C.; Hyka-Nouspikel, N.; Jungo, F.; Keller, G.; Kerhornou, A.; Lara, V.; Le Mercier, P.; Lieberherr, D.; Lombardot, T.; Martin, X.; Masson, P.; Morgat, A.; Neto, T.B.; Paesano, S.; Pedruzzi, I.; Pilbout, S.; Pourcel, L.; Pozzato, M.; Pruess, M.; Rivoire, C.; Sigrist, C.; Sonesson, K.; Stutz, A.; Sundaram, S.; Tognolli, M.; Verbregue, L.; Wu, C.H.; Arighi, C.N.; Arminski, L.; Chen, C.; Chen, Y.; Garavelli, J.S.; Huang, H.; Laiho, K.; McGarvey, P.; Natale, D.A.; Ross, K.; Vinayaka, C.R.; Wang, Q.; Wang, Y.; Yeh, L.-S.; Zhang, J.; Ruch, P.; Teodoro, D. UniProt: the universal protein knowledgebase in 2021. Nucleic Acids Res. 2021, 49, D480D489, https://doi.org/10.1093/nar/gkaa1100.

31. Gupta, S.; Kapoor, P.; Chaudhary, K.; Gautam, A.; Kumar, R.; Raghava, G.P.S. In silico approach for predicting toxicity of peptides and proteins. PLoS One 2013, 8, e73957, https://doi.org/10.1371/journal.pone.0073957.

32. Dimitrov, I.; Bangov, I.; Flower, D.R.; Doytchinova, I. AllerTOP v.2-a server for in silico prediction of allergens. J. Mol. Model. 2014, 20, 2278, https://doi.org/10.1007/s00894-014-2278-5.

33. Daina, A.; Michielin, O.; Zoete, V. SwissADME: a free web tool to evaluate pharmacokinetics, drug-likeness and medicinal chemistry friendliness of small molecules. Sci. Rep. 2017, 7, 42717, https://doi.org/10.1038/srep42717.

34. Mathur, D.; Singh, S.; Mehta, A.; Agrawal, P.; Raghava, G.P.S. In silico approaches for predicting the halflife of natural and modified peptides in blood. PLoS One 2018, 13, e0196829, https://doi.org/10.1371/journal.pone.0196829.

35. Iwaniak, A.; Minkiewicz, P.; Darewicz, M.; Sieniawski, K.; Starowicz, P. BIOPEP database of sensory peptides and amino acids. Food Res. Int. 2016, 85, 155-161, https://doi.org/10.1016/j.foodres.2016.04.031.

36. Zhou, P.; Jin, B.; Li, H.; Huang, S.-Y. HPEPDOCK: a web server for blind peptide-protein docking based on a hierarchical algorithm. Nucleic Acids Res. 2018, 46, W443-W450, https://doi.org/10.1093/nar/gky357.

37. Burley, S.K.; Bhikadiya, C.; Bi, C.; Bittrich, S.; Chen, L.; Crichlow, G. V.; Christie, C.H.; Dalenberg, K.; Di Costanzo, L.; Duarte, J.M.; Dutta, S.; Feng, Z.; Ganesan, S.; Goodsell, D.S.; Ghosh, S.; Green, R.K.; Guranović, V.; Guzenko, D.; Hudson, B.P.; Lawson, C.L.; Liang, Y.; Lowe, R.; Namkoong, H.; Peisach, E.; Persikova, I.; Randle, C.; Rose, A.; Rose, Y.; Sali, A.; Segura, J.; Sekharan, M.; Shao, C.; Tao, Y.-P.; Voigt, M.; Westbrook, J.D.; Young, J.Y.; Zardecki, C.; Zhuravleva, M. RCSB protein data bank: powerful new tools for exploring 3D structures of biological macromolecules for basic and applied research and education in fundamental biology, biomedicine, biotechnology, bioengineering and energy sciences. Nucleic Acids Res. 2021, 49, D437-D451, https://doi.org/10.1093/nar/gkaa1038.

38. Masuyer, G.; Schwager, S.L.U.; Sturrock, E.D.; Isaac, R.E.; Acharya, K.R. Molecular recognition and regulation of human angiotensin-i converting enzyme (ACE) activity by natural inhibitory peptides. Sci. Rep. 2012, 2, 717, https://doi.org/10.1038/srep00717.

39. Hiramatsu, H.; Yamamoto, A.; Kyono, K.; Higashiyama, Y.; Fukushima, C.; Shima, H.; Sugiyama, S.; Inaka, K.; Shimizu, R. The crystal structure of human dipeptidyl peptidase IV (DPPIV) complex with diprotin a. Biol. Chem. 2004, 385, 561-564, https://doi.org/10.1515/BC.2004.068.

40. Schöning-Stierand, K.; Diedrich, K.; Fährrolfes, R.; Flachsenberg, F.; Meyder, A.; Nittinger, E.; Steinegger, R.; Rarey, M. ProteinsPlus: interactive analysis of protein-ligand binding interfaces. Nucleic Acids Res. 2020, 48, W48-W53, https://doi.org/10.1093/nar/gkaa235.

41. Fährrolfes, R.; Bietz, S.; Flachsenberg, F.; Meyder, A.; Nittinger, E.; Otto, T.; Volkamer, A.; Rarey, M. ProteinsPlus: a web portal for structure analysis of macromolecules. Nucleic Acids Res. 2017, 45, W337W343, https://doi.org/10.1093/nar/gkx333.

42. Laskowski, R.A.; Swindells, M.B. LigPlot+: multiple ligand-protein interaction diagrams for drug discovery. J. Chem. Inf. Model. 2011, 51, 2778-2786, https://doi.org/10.1021/ci200227u.

43. Wallace, A.C.; Laskowski, R.A.; Thornton, J.M. LIGPLOT: a program to generate schematic diagrams of protein-ligand interactions. Protein Eng. Des. Sel. 1995, 8, 127-134, https://doi.org/10.1093/protein/8.2.127.

44. Ibrahim, M.A.; Bester, M.J.; Neitz, A.W.; Gaspar, A.R.M. Tuber storage proteins as potential precursors of bioactive peptides: an in silico analysis. Int. J. Pept. Res. Ther. 2018, 25, 437-446, https://doi.org/10.1007/S10989-018-9688-7.

45. Panjaitan, F.C.A.; Gomez, H.L.R.; Chang, Y.-W. In silico analysis of bioactive peptides released from giant 
grouper (Epinephelus lanceolatus) roe proteins identified by proteomics approach. Molecules 2018, 23, 2910, https://doi.org/10.3390/MOLECULES23112910.

46. Kartal, C.; Kaplan Türköz, B.; Otles, S. Prediction, identification and evaluation of bioactive peptides from tomato seed proteins using in silico approach. J. Food Meas. Charact. 2020, 14, 1865-1883, https://doi.org/10.1007/s11694-020-00434-z.

47. Szerszunowicz, I.; Nałęcz, D. The use of uniprotkb/biopep for the analysis of oat globulin physicochemical parameters and bioactivity. Czech J. Food Sci. 2018, 36, 119-125, https://doi.org/10.17221/455/2016-CJFS.

48. Van Platerink, C.J.; Janssen, H.G.M.; Haverkamp, J. Application of at-line two-dimensional liquid chromatography-mass spectrometry for identification of small hydrophilic angiotensin I-inhibiting peptides in milk hydrolysates. Anal. Bioanal. Chem. 2008, 391, 299-307, https://doi.org/10.1007/s00216-008-19903.

49. Matsufuji, H.; Matsui, T.; Nakashima, M.; Osajima, Y.; Seki, E.; Osajima, K. Angiotensin I-converting enzyme inhibitory peptides in an alkaline protease hydrolyzate derived from sardine muscle. Biosci. Biotechnol. Biochem. 1994, 58, 2244-2245, https://doi.org/10.1271/bbb.58.2244.

50. Nakahara, T.; Sano, A.; Yamaguchi, H.; Sugimoto, K.; Chikata, H.; Kinoshita, E.; Uchida, R. Antihypertensive effect of peptide-enriched soy sauce-like seasoning and identification of its angiotensin Iconverting enzyme inhibitory substances. J. Agric. Food Chem. 2010, 58, 821-827, https://doi.org/10.1021/jf903261h.

51. Seki, E.; Yamamoto, A.; Fujiwara, Y.; Yamane, T.; Satsu, H.; Ohkubo, I. Dipeptidyl peptidase-IV inhibitory activity of katsuobushi-derived peptides in Caco-2 cell assay and oral glucose tolerance test in icr mice. $J$. Agric. Food Chem. 2020, 68, 6355-6367, https://doi.org/10.1021/acs.jafc.0c01942.

52. Corrochano, A.R.; Cal, R.; Kennedy, K.; Wall, A.; Murphy, N.; Trajkovic, S.; O'Callaghan, S.; Adelfio, A.; Khaldi, N. Characterising the efficacy and bioavailability of bioactive peptides identified for attenuating muscle atrophy within a Vicia faba-derived functional ingredient. Curr. Res. Food Sci. 2021, 4, 224-232, https://doi.org/10.1016/j.crfs.2021.03.008.

53. Miner-Williams, W.M.; Stevens, B.R.; Moughan, P.J. Are Intact Peptides Absorbed from the Healthy Gut in the Adult Human?. Nutr. Res. Rev. 2014, 27, 308-329, https://doi.org/10.1017/S0954422414000225.

54. Amigo, L.; Hernández-Ledesma, B. Current Evidence on the Bioavailability of Food Bioactive Peptides. Molecules 2020, 25, 4479, https://doi.org/10.3390/molecules25194479.

55. Iwaniak, A.; Hrynkiewicz, M.; Bucholska, J.; Minkiewicz, P.; Darewicz, M. Understanding the nature of bitter-taste di- and tripeptides derived from food proteins based on chemometric analysis. J. Food Biochem. 2019, 43, e12500, https://doi.org/10.1111/JFBC.12500.

56. Ishibashi, N.; Sadamori, K.; Yamamoto, O.; Kanehisa, H.; Kouge, K.; Kikuchi, E.; Okai, H.; Fukui, S. Bitterness of phenylalanine- and tyrosine-containing peptides. Agric. Biol. Chem. 1987, 51, 3309-3313, https://doi.org/10.1080/00021369.1987.10868574.

57. Lan, V.T.T.; Ito, K.; Ohno, M.; Motoyama, T.; Ito, S.; Kawarasaki, Y. Analyzing a dipeptide library to identify human dipeptidyl peptidase IV inhibitor. Food Chem. 2015, 175, 66-73, https://doi.org/10.1016/j.foodchem.2014.11.131.

58. Cheung, H.S.; Wang, F.L.; Ondetti, M.A.; Sabo, E.F.; Cushman, D.W. Binding of peptide substrates and inhibitors of angiotensin-converting enzyme. Importance of the $\mathrm{COOH}$-terminal dipeptide sequence. J. Biol. Chem. 1980, 255, 401-407, https://doi.org/10.1016/s0021-9258(19)86187-2.

59. Liang, F.; Shi, Y.; Shi, J.; Zhang, T.; Zhang, R. A novel angiotensin-i-converting enzyme (ACE) inhibitory peptide IAF (Ile-Ala-Phe) from pumpkin seed proteins: in silico screening, inhibitory activity, and molecular mechanisms. Eur. Food Res. Technol. 2021, 1-11, https://doi.org/10.1007/S00217-021-03783-1.

60. Vercruysse, L.; Van Camp, J.; Morel, N.; Rougé, P.; Herregods, G.; Smagghe, G. Ala-Val-Phe and Val-Phe: ACE inhibitory peptides derived from insect protein with antihypertensive activity in spontaneously hypertensive rats. Peptides 2010, 31, 482-488, https://doi.org/10.1016/J.PEPTIDES.2009.05.029.

61. Nongonierma, A.B.; Mooney, C.; Shields, D.C.; Fitzgerald, R.J. In silico approaches to predict the potential of milk protein-derived peptides as dipeptidyl peptidase IV (DPP-IV) inhibitors. Peptides 2014, 57, 43-51, https://doi.org/10.1016/J.PEPTIDES.2014.04.018.

62. Juillerat-Jeanneret, L. Dipeptidyl peptidase IV and its inhibitors: therapeutics for type 2 diabetes and what else?. J. Med. Chem. 2014, 57, 2197-2212, https://doi.org/10.1021/jm400658e.

63. Wong, F.-C.; Ong, J.-H.; Chai, T.-T. SARS-CoV-2 spike protein-, main protease- and papain-like-proteasetargeting peptides from seed proteins following gastrointestinal digestion: an in silico study. Phytomedicine Plus 2021, 1, 100016, https://doi.org/10.1016/j.phyplu.2020.100016. 
64. Iheagwam, F.N.; Ogunlana, O.O.; Chinedu, S.N. Model optimization and in silico analysis of potential dipeptidyl peptidase IV antagonists from GC-MS identified compounds in Nauclea latifolia leaf extracts. Int. J. Mol. Sci. 2019, 20, 5913, https://doi.org/10.3390/ijms20235913.

65. Xue, L.; Yin, R.; Howell, K.; Zhang, P. Activity and bioavailability of food protein-derived angiotensin-Iconverting enzyme-inhibitory peptides. Compr. Rev. Food Sci. Food Saf. 2021, 20, 1150-1187, https://doi.org/10.1111/1541-4337.12711.

66. Wang, X.; Yu, H.; Xing, R.; Li, P. Characterization, preparation, and purification of marine bioactive peptides. Biomed Res. Int. 2017, 2017, 1-16, https://doi.org/10.1155/2017/9746720.

67. Imai, K.; Ji, D.; Nwachukwu, I.D.; Agyei, D.; Udenigwe, C.C. Bioinformatics and chemometrics for discovering biologically active peptides from food proteins. In Comprehensive Foodomics; Cifuentes, A., Ed.; Elsevier 2021, 482-494, https://doi.org/10.1016/B978-0-08-100596-5.22878-3. 